\title{
Surface Modification of SUS304 Stainless Steel Using Carbon Push-Ahead Effect by Low Temperature Plasma Nitriding
}

\author{
Masato Tsujikawa ${ }^{1}$, Daisuke Yoshida ${ }^{1, *}$, Naohiko Yamauchi ${ }^{2}$, Nobuhiro Ueda $^{2}$ and Takumi Sone ${ }^{2}$ \\ ${ }^{1}$ Graduate School of Engineering, Osaka Prefecture University, Sakai 599-8531, Japan \\ ${ }^{2}$ Technology Research Institute of Osaka Prefecture, Izumi 594-1157, Japan
}

Low temperature nitriding can harden the steel surface. However, the consequent thickness is limited because it depends on the formation of non-equilibrium phase at low temperature diffusion treatment. The hardness drops abruptly at the interface between the treated layer and the substrate as a result of nitriding. In this paper, duplex surface layers produced by combinations of carburizing and nitriding were developed using the carbon push-ahead effect of nitriding using relatively low-temperature plasma treatment. The location of the low-temperature carburized layer was pushed ahead following nitriding to form a support layer for a hard nitrided surface layer. The treatment combination was optimized for a thicker hard layer with good corrosion resistance.

(Received November 8, 2004; Accepted February 21, 2005; Published April 15, 2005)

Keywords: austenitic stainless steel, surface improvement, plasma nitriding, carburizing, corrosion resistance

\section{Introduction}

Low temperature plasma nitriding can harden the surfaces of austenitic stainless steels without degrading corrosion resistance. It does so by formation of a non-equilibrium precipitation free layer: the so called "S phase" or "expanded austenite". Despite its very high nitrogen content, the $S$ phase has no chromium nitrides that consume the dissolved chromium. ${ }^{1-4)}$

However, it is difficult to produce a thicker precipitationfree $S$ phase layer. A high temperature and long time treatment should not be applied to suppress formation of chromium nitrides. ${ }^{5)}$ Furthermore, as a characteristic feature of nitrided steels, the hardness profile of the treated steel shows a steep change in hardness at the border separating the nitrided layer and the substrate. ${ }^{5)}$ Such a change in mechanical properties would be gentler if we inserted a layer of intermediate hardness underneath the thin hard $S$ phase layer.

Low-temperature plasma carburizing of austenitic stainless steels also forms a hard and precipitation-free surface layer. The carburized $\mathrm{S}$ phase has a thicker case, more moderate hardness distribution, and lower layer hardness than the nitrided $\mathrm{S}$ phase does. ${ }^{6,7)}$

The dissolved carbon is pushed ahead by the incoming nitrogen, thereby accumulating beyond the nitrided layer by low temperature nitriding. ${ }^{4,8-11)}$ Such carbon accumulation has also been reported to result from simultaneous nitriding and carburizing. ${ }^{12)}$ The authors have also clarified that low temperature carburized layers are pushed-ahead by low temperature nitriding. Sequential carburizing and nitriding produce clear duplex surface layers. ${ }^{13)}$

The flexibility of design for an austenitic stainless steel surface layer would be wider if we were able to control the location of the carburized layer using this carbon push-ahead effect by nitriding. This study seeks to determine the optimum surface structure by controlling the microstructure using various combinations of carburizing and nitriding. Corrosion and wear resistance of these combination-treated samples were evaluated respectively using saltwater immersion test and dry slide friction test.
Table 1 Chemical composition of SUS304 sample (mass\%).

\begin{tabular}{cccccccccc}
\hline $\mathrm{C}$ & $\mathrm{Si}$ & $\mathrm{Mn}$ & $\mathrm{P}$ & $\mathrm{S}$ & $\mathrm{Ni}$ & $\mathrm{Cr}$ & $\mathrm{Mo}$ & $\mathrm{Cu}$ & $\mathrm{Fe}$ \\
\hline 0.06 & 0.4 & 0.94 & 0.037 & 0.003 & 8.3 & 18.8 & 0.21 & 0.31 & Bal.
\end{tabular}

\section{Experimental Procedure}

The material used in this study is an austenitic stainless steel that satisfies the JIS SUS304 grade. Table 1 lists the steel's chemical composition. Specimen plates were solutiontreated at $1303 \mathrm{~K}$ for $2.7 \mathrm{ks}$. Then they were dry ground slightly to the specimen shape of $25 \mathrm{~mm}$ width, $50 \mathrm{~mm}$ length, and $5 \mathrm{~mm}$ thickness. These preparations gave the specimens a fully austenitic structure, as confirmed by X-ray diffraction analysis.

Plasma treatments were performed individually with a laboratory-size apparatus with a simple DC power source. Each specimen, attached with a thermocouple, was set in the furnace as a cathode. After evacuation to $1.33 \cdot 10^{-1} \mathrm{~Pa}$, the mixed gas pressure for each specimen was adjusted to $6.67 \cdot 10^{2} \mathrm{~Pa}$. Subsequently, specimens were heated to $673 \mathrm{~K}$ by the plasma bombardment. Total respective processing time was set as $28.8 \mathrm{ks}(8 \mathrm{~h})$ as a constant.

Table 2 shows details of respective plasma treatments along with specimen symbols. For example, the $8 \cdot \mathrm{N}$ specimen was plasma treated at $673 \mathrm{~K}$ with a mixture of $80 \%$ nitrogen gas and $20 \%$ hydrogen gas for $8 \mathrm{~h}$. The $8(\mathrm{C}+\mathrm{N})$ specimen was treated by plasma carbo-nitriding process for $8 \mathrm{~h}$ at $673 \mathrm{~K}$ with a mixture of nitrogen, methane, and hydrogen gas. Similarly, the $4 \mathrm{C}-4 \mathrm{~N}$ specimen was first treated by plasma carburizing for $4 \mathrm{~h}$ at $673 \mathrm{~K}$, then secondarily treated by plasma nitriding for $4 \mathrm{~h}$ at $673 \mathrm{~K}$. In such a sequential process, the gas mixture changes were carried out within $10 \mathrm{~s}$ without any temperature change. After plasma treatment, specimens were allowed to cool in the evacuated apparatus.

$\mathrm{X}$-ray diffraction analysis (XRD), using $\mathrm{Cu}-\mathrm{K} \alpha(40 \mathrm{kV}$, $150 \mathrm{~mA}$ ) with a monochrometer, was undertaken to identify the crystal structure of the plasma treated layers. Glow 
Table 2 Plasma process used in this study.

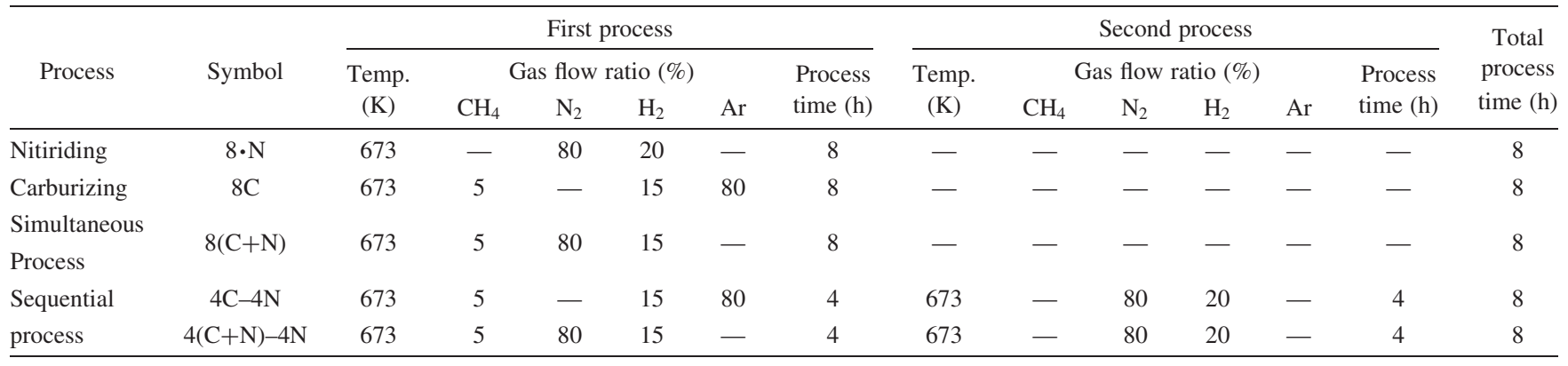

discharge optical emission spectrometry (GDOES) was used to analyze the elemental depth profiling of the treated surfaces. Hardness profiles of cross sections were measured using a Knoop hardness tester. Raman spectroscopy was also used to analyze the state of carbon at the treated surface. Microstructures and hardness profiles were measured at polished and aqua-regia etched sections.

Tribological properties were evaluated with a ball on a plate-type dry slide tribotester using an 8-mm-diameter ceramic $\left(\mathrm{Si}_{3} \mathrm{~N}_{4}\right)$ ball as the mated material. The applied load was constant at $18 \mathrm{~N}$. The coefficient of friction was monitored during the tests. After 4000 iterations of sliding friction, the specimen plate wear loss were measured using profilometry. Corrosion resistance of these specimens was estimated by saltwater immersion testing at room temperature with $10 \% \mathrm{NaCl}$ aqueous solution.

An evaluation for surface cracking was made using Vicker's hardness indentation at the surface of treated specimens. Specimens were indented using a dynamic ultra-micro-hardness tester (DUH-201S; Shimadzu Corp.) perpendicular to the processed surface. With increasing indentation force, cracks occurred suddenly at specimen surfaces. These threshold indentation forces for cracking were recorded.

\section{Results and Discussion}

\subsection{Characteristics of processed surface layers}

\subsubsection{Layer morphology and hardness profile}

Figure 1 shows cross-sectional views of treated specimens. Both $8 \mathrm{C}$ and $8 \cdot \mathrm{N}$ layers exhibit a similar bright appearance resulting from their resistance to the aqua regia that was used to reveal the microstructure. The $8 \mathrm{C}$ layer differs from the $8 \cdot \mathrm{N}$ layer in its features. The interface between the nitrided layer and the substrate is clear. However, the carburized layer presents a more gradual transition with the substrate. The two combined carburized and nitrided specimens, $4 \mathrm{C}+4 \mathrm{~N}$ and $4 \mathrm{C}-4 \mathrm{~N}$, have duplex layers irrespective of whether they were processed sequentially or simultaneously.

Figure 2 depicts the layer thickness as measured from these micrographs. The carburized specimen has a deeper layer than the nitrided specimen. Furthermore, combined processed specimens have deeper layers than the carburizedonly specimen. The hard layer thickness of the simultaneously carburized and nitrided specimen, $8(\mathrm{C}+\mathrm{N})$, was $145 \%$ that of the nitrided specimen; the $4 \mathrm{C}-4 \mathrm{~N}$ specimen has

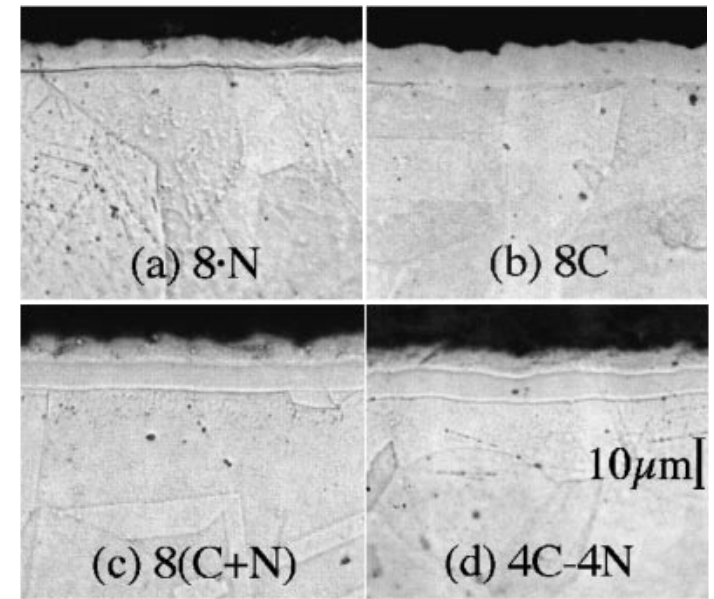

Fig. 1 Cross-section microstructures of plasma-treated SUS304 steels.

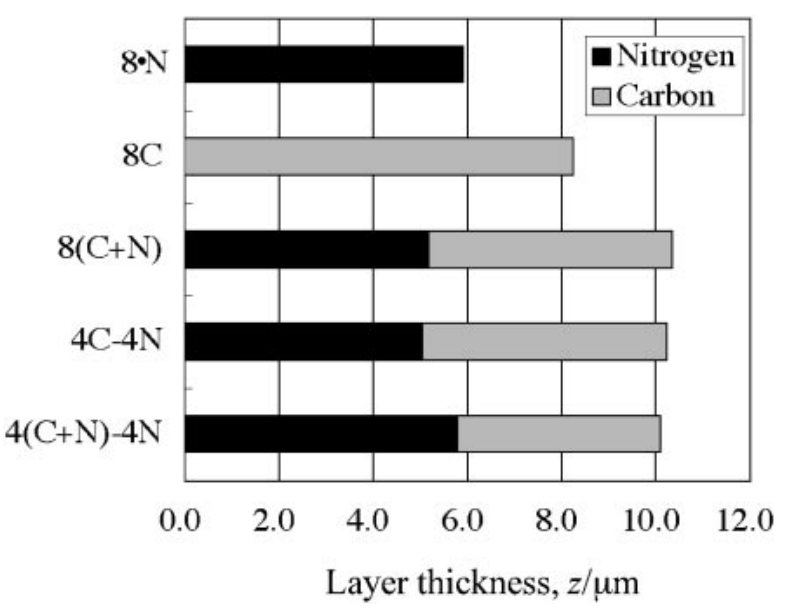

Fig. 2 Thickness of treated layer measured from micrographs.

a $150 \%$ deeper layer than the nitrided-only $8 \cdot \mathrm{N}$ specimen at an equal processing time.

The apparent coefficient of carbon diffusion was increased by the combination of nitriding. We require detailed examination to explain this effect, but the following assumption allows a qualitative explanation of the effect. That is, the interstitial sites near the chromium atom are more stable than other sites. ${ }^{14,15)}$ Nitrogen atoms are trapped by sites, because they have more affinity to chromium than 


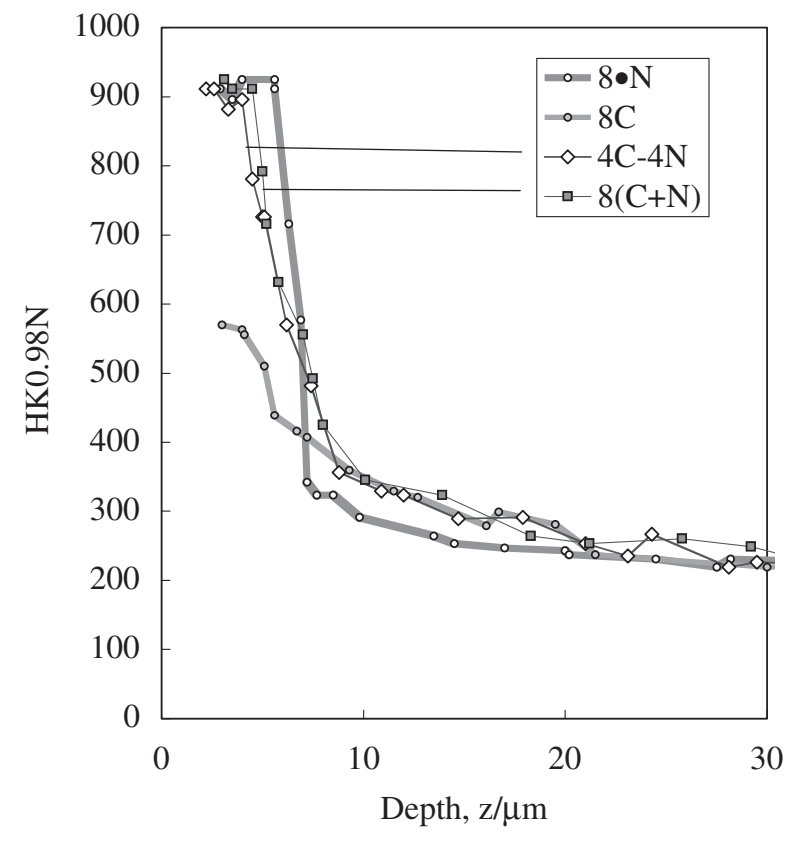

Fig. 3 Depth profiles of Knoop hardness.

carbon. ${ }^{11,16)}$ Carbon atoms can not remain in these trap sites because of the occupation by nitrogen. Interstitial atoms in these trap sites need more energy to escape to another sites. Carbon atoms from the surface diffuse only through the ordinary octahedral sites without trapping by chromium. Therefore, the aparent rate of carbon diffusion increases in the conditions with nitrogen.

Hardness profiles of these four specimens are shown in Fig. 3. The $8 \mathrm{C}$ specimen has maximum hardness of about $570 \mathrm{HK}$, which is far lower than the hardness of other specimens that were concerned with nitriding to a greater or lesser extent. Comparison of the hardness profiles of the $8 \mathrm{C}$ specimen with that of the $8 \cdot \mathrm{N}$ shows that the $8 \cdot \mathrm{N}$ specimen has a hard layer with an abrupt layer-core interface, whereas the carburizing produces a gradually decreasing hardness profile.

Two combined carburized and nitrided specimens, $8(\mathrm{C}+\mathrm{N})$ and $4 \mathrm{C}-4 \mathrm{~N}$, show similar hardness profiles. Combined processing produces gradually decreased hardness profiles with small bulging at about the $550 \mathrm{HK}$ range even though they have thinner layers of maximum hardness than that of the $8 \cdot \mathrm{N}$ specimen. The bulging is due to the inner carburized layer pushed-ahead by the presence of nitrogen.

\subsubsection{Elemental surface profiles}

Figure 4 shows elemental depth profiles of plasmaprocessed specimens. The carbon push-ahead effect of incoming nitrogen ${ }^{13,17)}$ is clearly visible in Figs. 4(a) and (d). Dissolved carbon is accumulated at the front of the nitrided layer in Fig. 4(a); a large amount of carburized carbon also accumulated beyond the nitrided layer in Fig. 4(d). However, some carbon remains in the nitrided layer of $4 \mathrm{C}-4 \mathrm{~N}$. A small peak of carbon is visible at the subsurface layer. ${ }^{13)}$

The simultaneously carburized and nitrided specimen $8(\mathrm{C}+\mathrm{N})$, as shown in Fig. 4(c), displayed high accumulation of carbon beyond the nitrided layer. The carbon concen-

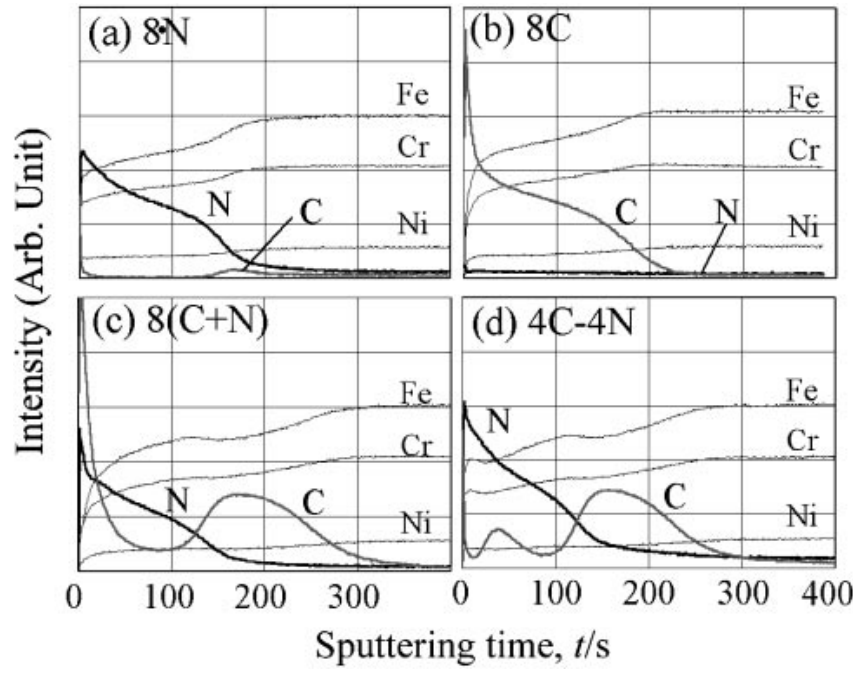

Fig. 4 GDOES elemental profiles of plasma-treated SUS304 steels.

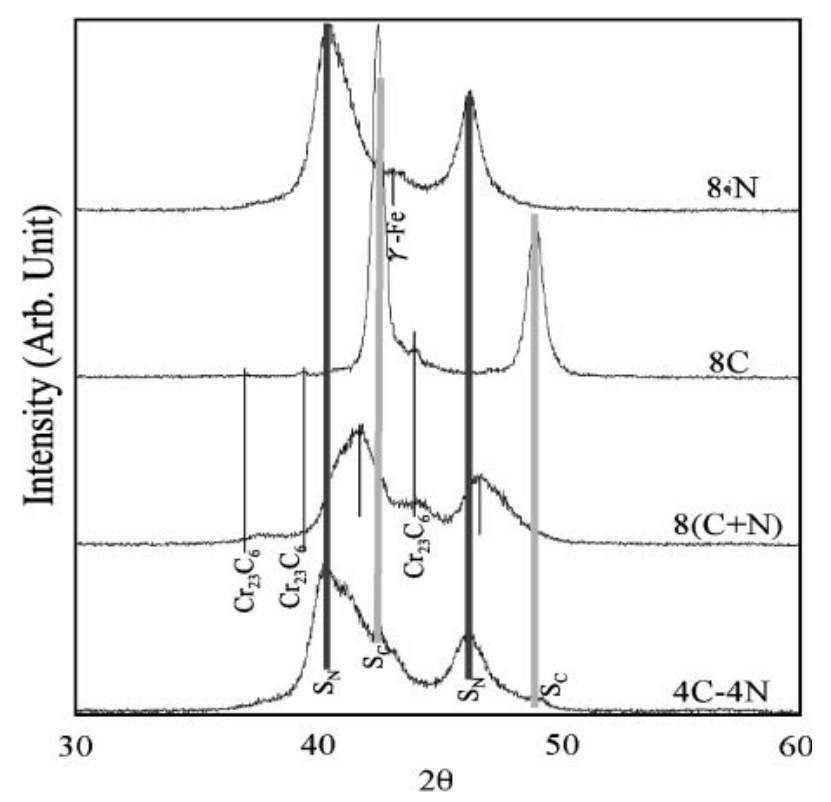

Fig. 5 Comparison of XRD patterns of treated specimens.

tration at the very surface of this specimen is as high as the carburized-only specimen. Contrary to this, the sequentially carburized and nitrided specimen $4 \mathrm{C}-4 \mathrm{~N}$, as shown in Fig. 4(d), has low carbon concentration at the surface.

\subsubsection{X-ray diffraction and raman spectrometry analy-} sis

Figure 5 shows XRD patterns of plasma processed specimens. The carburized specimen, $8 \mathrm{C}$, and nitrided specimen, $8 \cdot \mathrm{N}$, show a typical $\mathrm{S}$ phase by carbon and by nitrogen. The $\mathrm{X}$-ray diffraction pattern of $4 \mathrm{C}-4 \mathrm{~N}$ is fundamentally the sum of patterns of the nitrided specimen and carburized specimen. Peaks of nitrided $S$ phase $\left(S_{\mathrm{N}}\right)$ and carburized $S$ phase $\left(S_{\mathrm{C}}\right)$ appear separately in the pattern of the $4 \mathrm{C}-4 \mathrm{~N}$ specimen. However, in the pattern of $8(\mathrm{C}+\mathrm{N})$, the peaks that were inferred to indicate $S$ phase do not show separate characteristics of $S_{\mathrm{N}}$ and $S_{\mathrm{C}}$. They are positioned between $S_{\mathrm{N}}$ and $S_{\mathrm{C}}$ in the $8(\mathrm{C}+\mathrm{N})$ pattern. Presence of some chromium carbides was suspected in the $8 \mathrm{C}$ and $8(\mathrm{C}+\mathrm{N})$ specimens. 


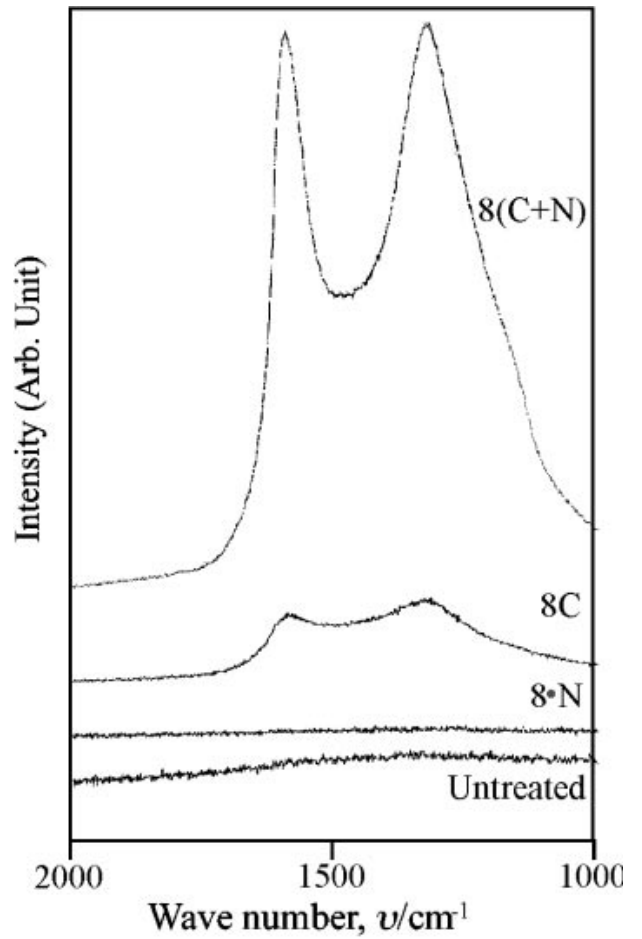

Fig. 6 Results of Raman spectrometry for carburized specimens.

Hues of plasma-treated surfaces of specimens varied according to their respective processes. Simultaneously combined processes, $8(\mathrm{C}+\mathrm{N})$, engendered the darkest semiglossed surface of all. The second darkest was the carburizedonly specimen surface. The nitrided-only specimen, $8 \cdot \mathrm{N}$, and the sequentially processed specimen, $4 \mathrm{C}-4 \mathrm{~N}$, yielded the brightest surfaces. In Fig. 6, Raman spectroscopy shows a glassy carbon ${ }^{18)}$ at the surface of the simultaneously processed specimen $8(\mathrm{C}+\mathrm{N})$.

\subsection{Wear properties}

Figure 7 shows a comparison of wear loss under dry sliding friction. The $8 \mathrm{C}$ specimen exhibits substandard wear resistance because of its low maximum hardness. The $4 \mathrm{C}-4 \mathrm{~N}$ specimen and the $8 \cdot \mathrm{N}$ specimen demonstrated excellent wear resistance.

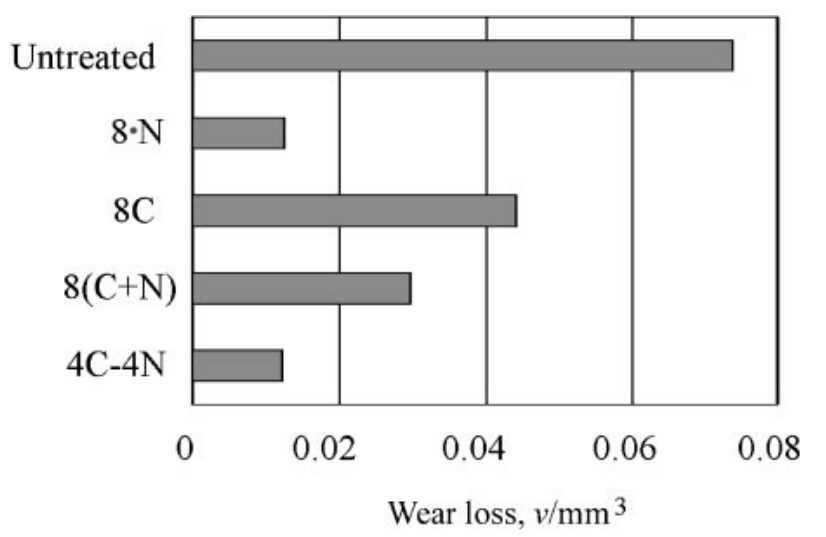

Fig. 7 Comparison of wear loss under dry sliding condition.
Table 3 Saltwater immersion test result (room temperature).

\begin{tabular}{lcccc}
\hline \multirow{2}{*}{ Specimen } & \multicolumn{4}{c}{ Immersion time } \\
\cline { 2 - 5 } & $8 \mathrm{~h}$ & $24 \mathrm{~h}$ & $72 \mathrm{~h}$ & $240 \mathrm{~h}$ \\
\hline $8 \cdot \mathrm{N}$ & 0 & $\bigcirc$ & $\bigcirc$ & $\bigcirc$ \\
$8 \mathrm{C}$ & $\bigcirc$ & $\bigcirc$ & $\times$ & $\times$ \\
$8(\mathrm{C}+\mathrm{N})$ & $\times$ & $\times \times$ & $\times \times$ & $\times \times$ \\
$4 \mathrm{C}-4 \mathrm{~N}$ & $\bigcirc$ & $\bigcirc$ & $\bigcirc$ & $\bigcirc$ \\
$4(\mathrm{C}+\mathrm{N})-4 \mathrm{~N}$ & 0 & $\bigcirc$ & $\bigcirc$ & 0 \\
\hline
\end{tabular}

On the other hand, the wear of the $8(\mathrm{C}+\mathrm{N})$ specimen proceeded at over twice the rate of the $8 \cdot \mathrm{N}$ specimen even though its maximum hardness is as high as the $8 \cdot \mathrm{N}$ specimen: a hardness drop at the surface was suspected. The coefficient of friction of the $8(\mathrm{C}+\mathrm{N})$ specimen was 0.4 in the early stage of friction under 150 turns. Other specimens showed a coefficient of friction of 0.7 .

\subsection{Corrosion resistance}

Table 3 shows results of saltwater immersion test. The nitrided-only specimen, $8 \cdot \mathrm{N}$, has excellent corrosion resistance, just as untreated SUS304 steel. However, the carburized-only specimen, $8 \mathrm{C}$, showed rust within $72 \mathrm{~h}$. The formation of chromium carbide, as shown in Fig. 5, affects corrosion resistance of the $8 \mathrm{C}$ specimen.

Saltwater immersion tests indicated a clear distinction between simultaneous processing and sequential processing. Simultaneously carburized and nitrided specimen, $8(\mathrm{C}+\mathrm{N})$, began to form reddish brown rust within $1 \mathrm{~h}$. In contrast, the sequentially carburized and nitrided specimen, $4 \mathrm{C}-4 \mathrm{~N}$, never developed rust. Chromium carbide formation causes this difference.

Figure 4 shows that specimens with poor corrosion resistance have high carbon concentration at the surface. Supersaturated carbon may begin to form carbides over the long duration of plasma processing, even at the relatively low temperature of $673 \mathrm{~K}$.

\subsection{Surface material design by combined process of nitriding and carburizing}

These results suggest the optimum surface design as a combination of carburizing and nitriding. The process thickens the hard layer by simultaneous nitriding and carburizing as the first process. The surface concentration peak of carbon must be pushed-ahead by the nitriding as a second process for corrosion resistance. The process details are listed in Table 2 as $4(\mathrm{C}+\mathrm{N})-4 \mathrm{~N}$. This process thickens the nitrogen-S phase by nitriding throughout the process.

The microstructure and the GDOES profile of $4(\mathrm{C}+\mathrm{N})-4 \mathrm{~N}$ specimen are shown respectively in Fig. 8 and Fig. 9. The duplex layer thickness is greater than $11 \mu \mathrm{m}$. Carbon concentration at the surface is reduced by the second nitriding process. The hardness profile of this specimen is displayed in Fig. 10. The thickness of the maximum hardness is identical to that of the $8 \cdot \mathrm{N}$ specimen. Bulging of the intermediate hardness range by carbon $S$ phase is apparent. Corrosion resistance, already listed in Table 3 , is as good as the $4 \mathrm{C}-4 \mathrm{~N}$ process. 


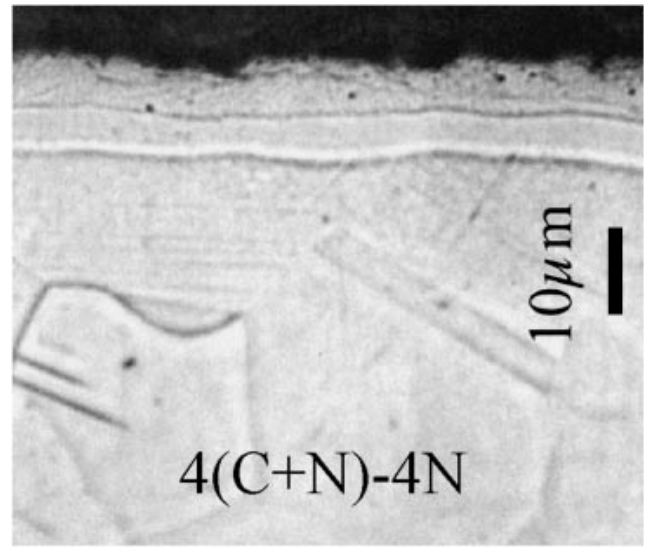

Fig. 8 Microstructure of the simultaneously carburized and nitrided then nitrided specimen, $4(\mathrm{C}+\mathrm{N})-4 \mathrm{~N}$.

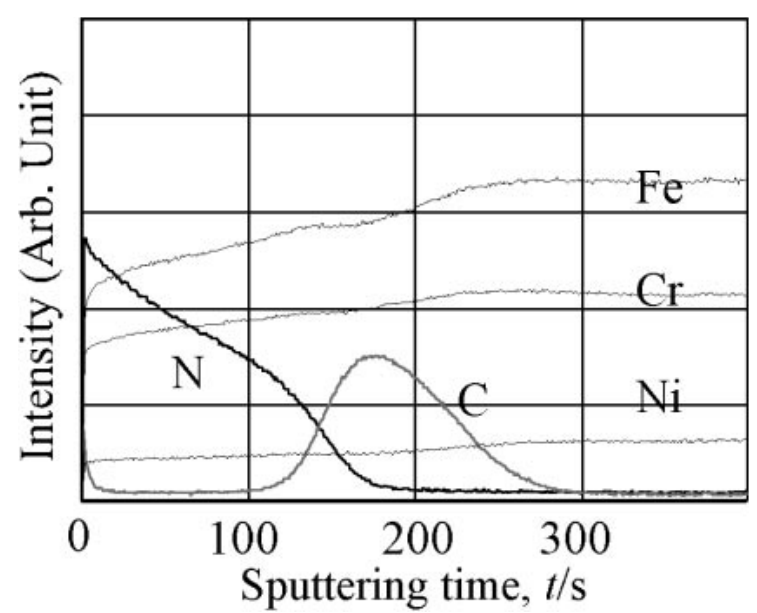

Fig. 9 GDOES profile of the $4(\mathrm{C}+\mathrm{N})-4 \mathrm{~N}$ specimen.

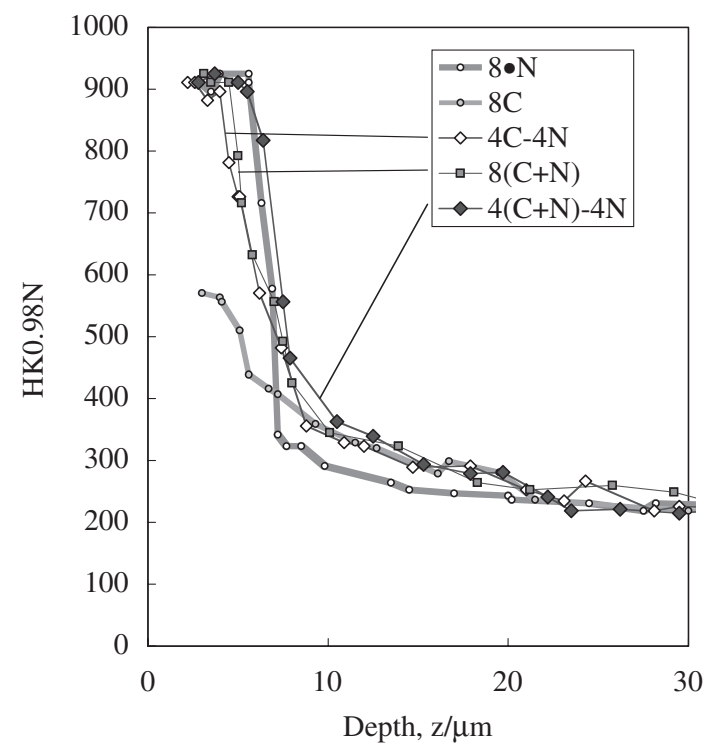

Fig. 10 Hardness depth profile of the $4(C+N)-4 N$ specimen.

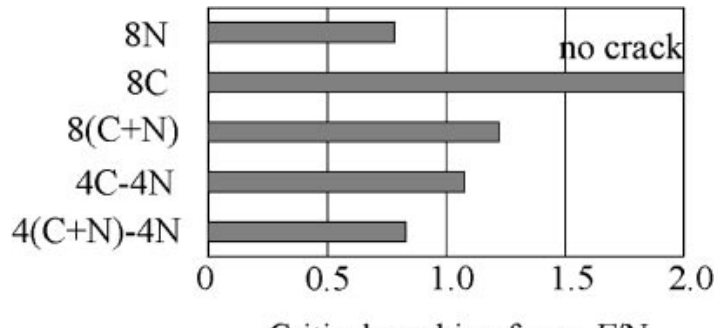

Critical cracking force, $F / \mathrm{N}$

Fig. 11 Threshold cracking forces of specimens under surface indentation test.

\subsection{Surface cracking by hardness indentation}

Figure 11 shows surface indentation cracking test results. The nitrided-only specimen, $8 \cdot \mathrm{N}$, cracked at the smallest indentation force of all. The carburized-only specimen, 8C, did not crack below $2 \mathrm{~N}$. The carburized layer has a higher flexibility than the nitrided layer has because of its moderate hardness and toughness. ${ }^{5)}$ The $8(\mathrm{C}+\mathrm{N})$ specimen and the $4 \mathrm{C}-$ $4 \mathrm{~N}$ specimen show greater threshold force than the $8 \cdot \mathrm{N}$ specimen because the thickness of hard nitrided layers is small and the flexible carburized layer supports them from the back. The critical force of $4(\mathrm{C}+\mathrm{N})-4 \mathrm{~N}$ specimen was low compared to that of $8(\mathrm{C}+\mathrm{N})$ and $4 \mathrm{C}-4 \mathrm{~N}$ with thin hard nitrided layers. However, the critical cracking force of the $4(\mathrm{C}+\mathrm{N})-4 \mathrm{~N}$ specimen was slightly better than that of the $8 \cdot \mathrm{N}$ specimen. In consideration of identical thickness of the hard nitrided layers, the result shows the effect of bulging underneath the nitrided layer in the hardness profile.

\section{Conclusions}

The combinations of low temperature nitriding and carburizing processed to 304 type austenitic stainless steel to thicken the case depth and to improve the hardness profile of nitriding. Several conclusions can be drawn concerning surface layer properties.

(1) Plasma-nitriding pushed ahead the plasma-carburized layer. This formed duplex surface layers of different hardness. The total thickness of the case was increased by the combination of carburizing and nitriding.

(2) Raman spectroscopy revealed some kind of a glassy carbon at the surface of a simultaneously carburized and nitrided specimen.

(3) The duplex structure by sequential carburizing and nitriding has excellent corrosion resistance as evaluated by saltwater immersion tests. However, the simultaneously carburized and nitrided specimen has the poorest corrosion resistance of all.

(4) Simultaneously carburized and nitrided then nitrided specimen showed a thicker maximum hardness layer and the deepest treated layer. This specimen has similar excellent corrosion resistance to that of the sequentially processed specimen. 


\section{REFERENCES}

1) K. Ichii, K. Fujimura and T. Takase: Netsu Shori 25 (1985) 191-196.

2) Z. L. Zhang and T. Bell: Surf. Eng. 1 (1985) 131-136.

3) K.-T. Rie and E. Broszeit: Surf. Coat. Technol. 76-77 (1995) 425-436.

4) N. Yamauchi, N. Ueda, K. Demizu, A. Okamoto, T. Sone, K. Oku, T. Kouda, K. Ichii and K. Akamatsu: Proc. Int. Current Status Seminar on Thermochemical Surf. Eng. Osaka (2000) 247-261.

5) T. Bell and Y. Sun: Proc. Int. Current Status Seminar on Thermochemical Surf. Eng. Osaka (2000) 275-288.

6) Y. Sun, X. Y. Li and T. Bell: Surf. Eng. 15 (1999) 49-54.

7) Y. Sun, X. Y. Li and T. Bell: Mater. Sci. Technol. 15 (1999) 11711178.

8) M. P. Fewell, P. Garlick, J. M. Priest, P. T. Burke, N. Dytlewski, K. E. Prince, K. T. Short, R. G. Elliman, H. Timmers, T. D. M. Weijers and B. Gong: Proc. Int. Current Status Seminar on Thermochemical Surf. Eng. Osaka (2000) 177-200.

9) M. J. Baldwin, S. Kumar, J. M. Priest, M. P. Fewell, K. E. Prince and K.
T. Short: Thin Solid Films 345 (1999) 108-112.

10) X. Li, Y. Sun and T. Bell: Z. Metallkd. 90 (1999) 901-907.

11) S. Parascandola, W. Möller and D. L. Williamson: Proc. Int. Current Status Seminar on Thermochemical Surf. Eng. Osaka (2000) 201-214.

12) C. Blawert, B. L. Mordike, G. A. Collins, K. T. Short, Y. Jiraskova, O. Schneeweiss and V. Perina: Surf. Coat. Technol. 128-129 (2000) 219225.

13) M. Tsujikawa, N. Yamauchi, N. Ueda, T. Sone and Y. Hirose: Surf. Coat. Technol. 193/1-3 (2004) 309-313.

14) D. L. Douglass, G. Thomas and W. R. Roser: Corrosion 20 (1964) 1528.

15) K. Oda, N. Kondo and K. Shibata: ISIJ Int. 30 (1990) 625-632.

16) M. Murayama, K. Hono, H. Hirukawa, T. Ohmura and S. Matsuoka: Scr. Mater. 41 (1999) 467-473.

17) A. Leyland, D. B. Lewis, P. R. Stevenson and A. Matthews: Surf. Coat. Technol. 62 (1993) 608-617.

18) H. Hamaguchi and A. Hirakawa ed.: Raman spectroscopy, (Japan. Institute of Spectrometry, Tokyo, 1988), p. 180. 